\title{
The Effect of the Preparation Method of Pd-Doped Cobalt Spinel on the Catalytic Activity in Methane Oxidation Under Lean Fuel Conditions
}

\author{
G. Ercolino ${ }^{1}$ A. Grodzka ${ }^{2}$ G. Grzybek ${ }^{2}$ P. Stelmachowski ${ }^{2}$ • \\ S. Specchia ${ }^{1}$ A. Kotarba ${ }^{2}$
}

Published online: 5 May 2016

(c) The Author(s) 2016. This article is published with open access at Springerlink.com

\begin{abstract}
In this work a series of cobalt spinel catalysts was synthesized by different methods and doped with $1 \mathrm{wt} \%$ of palladium via incipient wetness impregnation or solution combustion synthesis (SCS). Both undoped and Pd-doped spinels were characterized from the structural and surface point of view (XRD, XRF, $\mu R S$, BET, FESEM) and tested toward the oxidation of methane in lean conditions, in gas mixtures containing from 0.5 to 2 vol\% of $\mathrm{CH}_{4}$. These methane concentrations are typical of processes involving combustion of $\mathrm{CH}_{4}$ in lean conditions as the after-treatment of unconverted $\mathrm{CH}_{4}$ in compressed natural gas-fed vehicle exhausts, or the treatment of fugitive $\mathrm{CH}_{4}$ from leaks in coal mines. The temperature window for the catalytic activity of the undoped $\mathrm{Co}_{3} \mathrm{O}_{4}$ materials spread from 350 to $600{ }^{\circ} \mathrm{C}$. The preparation method affected the catalytic activity of undoped $\mathrm{Co}_{3} \mathrm{O}_{4}$, with the best catalytic activity related to the spinel prepared by SCS employing urea. The addition of $1 \mathrm{wt} \%$ of $\mathrm{Pd}$ lowered the temperature window for the catalytic activity to the range of $250-500{ }^{\circ} \mathrm{C}$, with insignificant differences for the various preparation methods. The beneficial effect of Pd-doping was assigned to the enhancement of the reduction of cobalt in the oxide structure.
\end{abstract}

S. Specchia

stefania.specchia@polito.it

$凶$ A. Kotarba

kotarba@chemia.uj.edu.pl

1 Department of Applied Science and Technology, Politecnico di Torino, Corso Duca degli Abruzzi 24, 10129 Turin, Italy

2 Faculty of Chemistry, Jagiellonian University in Kraków, ul. Ingardena 3, 30-060 Kraków, Poland
Keywords Cobalt spinel $\cdot$ Palladium $\cdot$ Methane combustion · Lean conditions · Urea - Glycine

\section{Introduction}

The methane $\left(\mathrm{CH}_{4}\right)$, carbon monoxide $(\mathrm{CO})$ or volatile organic compounds (VOCs) present at low concentrations are required to be removed from the various exhaust gases. Catalytic combustion of these compounds appears as the most feasible route for the gas cleaning [1]. The flameless combustion is ideal for highly diluted air/fuel streams, as the production of $\mathrm{NO}_{\mathrm{x}}$ is inhibited by the relatively low reaction temperature [2]. Typical processes involving combustion of $\mathrm{CH}_{4}$ in lean conditions are the after-treatment of unconverted $\mathrm{CH}_{4}$ in compressed natural gas-fed vehicle exhausts (ranging from 0.4 to 1 vol\%) [3, 4] or the treatment of fugitive $\mathrm{CH}_{4}$ from leaks in coal mines [5, 6], from gas transportation facilities such as pipelines and compressor stations [7, 8], from upstream oil and gas production facilities [9], and from other anthropogenic sources (ranging from 0.5 to 4 vol\%) [10, 11].

For the catalytic combustion of $\mathrm{CH}_{4}$ in lean conditions many different catalysts have been studied so far, ranging from noble metals, mainly Pd and/or Pt supported on oxides or mixed oxides [12-15], to perovskites [16-18], and non-noble oxides $[19,20]$. In particular, among non-noble oxides in recent years cobalt oxides attracted great attention thanks to their catalytic properties, useful in many different applications, for example as magnetic materials [21, 22], electrochemical devices [23, 24], and various catalytic systems [25-30].

Specifically, undoped and doped $\mathrm{Co}_{3} \mathrm{O}_{4}$ displays excellent performance towards the catalytic combustion of $\mathrm{CH}_{4}$ [31-35]. Recent studies demonstrated that when a high 
number of structural defects and a great amount of nonstoichiometric oxygen are available the catalytic activity is improved [34, 36, 37]. Moreover, the oxidation-reduction cycle between $\mathrm{Co}^{2+}$ and $\mathrm{Co}^{3+}$ could play a significant role for the catalytic combustion of $\mathrm{CH}_{4}[38,39]$. Thus, studying how different synthesis techniques can influence the properties of the $\mathrm{Co}_{3} \mathrm{O}_{4}$ could be of great interest to prepare highly active catalysts.

In this study, a comparative evaluation of $\mathrm{Co}_{3} \mathrm{O}_{4}$ and $1 \mathrm{wt} \% \mathrm{Pd} / \mathrm{Co}_{3} \mathrm{O}_{4}$ prepared following different synthesis techniques is proposed. Specifically, the undoped catalysts were prepared by precipitation and solution combustion synthesis (SCS) from two different precursors: urea or glycine. The Pd-doped catalysts were prepared by the incipient wetness impregnation (IWI) of the $\mathrm{Co}_{3} \mathrm{O}_{4}$ samples synthesized by precipitation or SCS. Furthermore, Pd-doped catalysts were synthesized also by one-shot SCS, by mixing directly the Pd precursor with the $\mathrm{Co}_{3} \mathrm{O}_{4}$ precursors, avoiding thus the IWI step. All of the prepared catalysts were then fully characterized by $\mathrm{N}_{2}$-BET, FESEM, XRD, XRF and micro-Raman spectroscopy $(\mu-\mathrm{RS})$. The activity of synthesized catalysts towards $\mathrm{CH}_{4}$ combustion in lean conditions was measured by means of a series of temperature programmed oxidations (TPO) considering three different methane feedstocks, $0.5,1$ and $2 \mathrm{vol} \%$ respectively, as representative feedstocks of typical processes involving methane combustion.

The IWI method is a commonly used technique for the synthesis of heterogeneous catalysts. The SCS is a technique being investigated so far to create materials with enhanced catalytic properties [2, 40]. It essentially means decomposing a material (typically the nitrate of the precursors leading to the desired final product) in the presence of a reducing agent (typically an organic fuel as glycine or urea) to create new structures with different properties through a redox reaction. The reaction involved in the SCS generates a significant volume of high-purity foamy elements because of the exothermicity of the redox reaction [2]. The relatively high surface area and high purity of the material are of great interest from the catalytic point of view. Preparing different morphologies of cobalt oxide was demonstrated recently as a strategy for improving the catalytic activity [39]. A controllable and selective synthesis method, able to influence the properties of new materials, the catalytic reactivity, the selectivity and the durability is very important from the industrial point of view [41]. The main goal of this study was to evaluate and understand the role of the synthesis method in the development of the catalytic properties of the prepared materials towards the methane combustion in lean conditions.

\section{Materials and Methods}

\subsection{Chemicals}

Cobalt(II) nitrate hexahydrate, $\mathrm{Co}\left(\mathrm{NO}_{3}\right)_{2} \cdot 6 \mathrm{H}_{2} \mathrm{O}(\geq 98 \%$ purity), palladium(II) nitrate hydrate, $\mathrm{Pd}\left(\mathrm{NO}_{3}\right)_{2} \cdot \mathrm{xH}_{2} \mathrm{O}$ ( $\geq 99 \%$ purity), ammonia carbonate, $\left(\mathrm{NH}_{4}\right)_{2} \mathrm{CO}_{3}(\geq 99 \%$ purity), glycine, $\mathrm{NH}_{2} \mathrm{CH}_{2} \mathrm{COOH}$ ( $\geq 99 \%$ purity) and urea, $\mathrm{CH}_{4} \mathrm{~N}_{2} \mathrm{O}$ ( $\geq 99 \%$ purity) were purchased from SigmaAldrich. Aqueous solutions were prepared using ultrapure water obtained from a Millipore Milli-Q system with a resistivity $>18 \mathrm{M} \Omega \mathrm{cm}$. Pure methane, oxygen, and nitrogen gases (purity $99.999 \%$ ) were supplied in cylinders provided by SIAD company and used as received.

\subsection{Catalysts Preparation}

Undoped cobalt spinel was synthesized by SCS using glycine or urea as organic fuels and cobalt nitrate [35], as well as by precipitation method [42].

For spinels prepared by SCS, a solution containing cobalt nitrate and the organic fuel was prepared, stirred at $120{ }^{\circ} \mathrm{C}$ to favor the dissolution of the reagents, and placed in an electric oven at $250{ }^{\circ} \mathrm{C}$ for $20 \mathrm{~min}$. According to the literature, for the optimal SCS spinels' synthesis glycine was added as $25 \%$ of the necessary stoichiometric amount [35], and urea was added as $84 \%$ of the necessary stoichiometric amount [43]. Obtained spinels by SCS were calcined at $600{ }^{\circ} \mathrm{C}$ for $4 \mathrm{~h}$ in static air. The spinel prepared by precipitation was obtained by a dropwise adding the ammonium carbonate to the solution of cobalt nitrate. Thus obtained precipitate was dried overnight and calcined at $400{ }^{\circ} \mathrm{C}$ for $2 \mathrm{~h}$ and re-calcined at $600{ }^{\circ} \mathrm{C}$ for $4 \mathrm{~h}$.

$\mathrm{Pd}$-doped catalysts were prepared by depositing $\mathrm{Pd}$ on each of the $\mathrm{Co}_{3} \mathrm{O}_{4}$ spinels by IWI with palladium nitrate solution at the level of $1 \mathrm{wt} \%$. A final calcination was done in static air for $4 \mathrm{~h}$ at $600{ }^{\circ} \mathrm{C}$.

Furthermore, $\mathrm{Pd} / \mathrm{Co}_{3} \mathrm{O}_{4}$ catalysts were synthesized also by one-shot SCS [35]: the necessary amounts of cobalt nitrate and palladium nitrate as precursors and organic fuel (glycine or urea) were dissolved together in aqueous solution at around $120{ }^{\circ} \mathrm{C}$ and then placed in an electric oven at $250{ }^{\circ} \mathrm{C}$ for $20 \mathrm{~min}$, following exactly the same procedure used for the preparation of $\mathrm{Co}_{3} \mathrm{O}_{4}$ alone. The obtained $\mathrm{Pd} / \mathrm{Co}_{3} \mathrm{O}_{4}$ catalysts were calcined in static air for $4 \mathrm{~h}$ at $600{ }^{\circ} \mathrm{C}$.

\subsection{Physicochemical Characterization}

The relative content of cobalt and palladium oxides in the investigated catalysts was determined with the use of Energy-Dispersive XRF spectrometer (Thermo Scientific, 
ARL QUANT'X). The X-rays of 4-50 kV (1 kV step) with the beam size of $1 \mathrm{~mm}$ were generated with the $\mathrm{Rh}$ anode. The detector used was a $3.5 \mathrm{~mm} \mathrm{Si}(\mathrm{Li})$ drifted crystal with a Peltier cooling $(\sim 185 \mathrm{~K})$. For quantitative analysis, the calibration with a series of metallic standards and the UniQuant software were used. The measured catalysts were in the form of discs, $10 \mathrm{~mm}$ in diameter, c.a. 1-2 $\mathrm{mm}$ in height, prepared by grinding the powder in an agate mortar and pressing under $5 \mathrm{MPa}$ in a hydraulic press.

Nitrogen physisorption was performed at $-196{ }^{\circ} \mathrm{C}$ on a Micromeritics ASAP 2020 instrument. Before the measurement, each sample (about $100 \mathrm{mg}$ ) was outgassed overnight at $150{ }^{\circ} \mathrm{C}$ in vacuum $(7 \mathrm{~Pa})$. The specific surface area (SSA) was evaluated by the BET method between 0.05 and $0.30 \mathrm{p} / \mathrm{p}^{\circ}$. The pore diameter distribution was evaluated by the Barrett-Joyner-Halenda (BJH) method, calibrated for cylindrical pores according to the improved Kruk-Jaroniec-Sayari (KJS) method, with the corrected form of the Kelvin equation, from the desorption branches of the isotherms.

Field-emission scanning electron microscopy (FESEM JEOL-JSM-6700F instrument) was performed to analyze the morphology of the spinels with and without Pd.

$\mathrm{X}$-ray diffraction (XRD) patterns were collected using a Philips X-Pert MPD X-ray diffractometer equipped with a $\mathrm{Cu} \mathrm{K} \mathrm{K}_{\alpha}$ radiation at $40 \mathrm{kV}$ and $30 \mathrm{~mA}$ to verify the effective composition of the sample and derive a qualitative indication of the presence of comparatively large noble metal crystallite from its eventually visible peaks. All powder samples were scanned over the $2 \theta$ range $20^{\circ}-70^{\circ}$ over $1 \mathrm{~h}$. The peaks were assigned according to the PCPFWIN database.

Raman spectroscopy was performed on a Renishaw InVia spectrometer equipped with a Leica DMLM confocal microscope and a CCD detector, with excitation wavelengths of 785 and $514 \mathrm{~nm}$. The Raman scattered light was collected in the spectral range $100-1000 \mathrm{~cm}^{-1}$. At least ten scans were accumulated to ensure a sufficient signal-tonoise ratio.

\subsection{Catalytic Tests}

The catalytic activity towards $\mathrm{CH}_{4}$ oxidation (temperature programmed oxidation, TPO) of the investigated catalysts was tested in a lab-scale fixed-bed microreactor (U-shape quartz tube with $4 \mathrm{~mm}$ ID) containing $0.1 \mathrm{~g}(0.4-0.6 \mathrm{~mm}$ in size obtained by disks of catalysts pressed at $5 \mathrm{MPa}$, grinded and sieved), of catalyst mixed with $0.9 \mathrm{~g}$ of $\mathrm{SiO}_{2}$ (0.2-0.7 $\mathrm{mm}$ in size, to prevent the catalytic bed clogging), sandwiched between two quartz wool layers. The microreactor, placed into a PID-regulated electrical oven, was fed with $0.1 \mathrm{NL} \min ^{-1}$ (equivalent to a weight space hourly velocity WHSV of $60 \mathrm{NL} \mathrm{s}^{-1} \mathrm{~g}_{\text {cat }}^{-1}$ ) of a gaseous mixture containing 2, 1 or $0.5 \mathrm{vol} \% \mathrm{CH}_{4}$ in $\mathrm{N}_{2}$, with an excess of oxygen ( $\lambda=8$, for all $\mathrm{CH}_{4}$ inlet concentrations). The micro-reactor temperature was measured by a K-type thermocouple placed inside the catalytic bed. $\mathrm{CH}_{4}-\mathrm{TPO}$ tests were performed by increasing the temperature of the microreactor up to $700{ }^{\circ} \mathrm{C}\left(50{ }^{\circ} \mathrm{C} \mathrm{min}{ }^{-1}\right)$ in a $\mathrm{N}_{2}$ stream $\left(0.1 \mathrm{NL} \mathrm{min}^{-1}\right)$, then switching the feed to the reactive stream $\left(\mathrm{CH}_{4} / \mathrm{O}_{2} / \mathrm{N}_{2}\right.$ in the desired amounts) until the $\mathrm{CH}_{4}$ combustion was complete. When this condition was reached, the oven was allowed to cool naturally. During the oven cooling phase, the reactor outlet dry gas concentrations were measured as a function of the temperature decrease by a continuous $\mathrm{ABB}$ analyzer (equipped with a NDIR module Uras 14 for $\mathrm{CO} / \mathrm{CO}_{2} / \mathrm{CH}_{4}$, and with a paramagnetic module Magnos 106 for $\mathrm{O}_{2}$ ). Sigma-shaped curves were obtained by plotting the $\mathrm{CH}_{4}$ conversion versus temperature. Each catalyst was tested first by flowing the mixture containing $2 \%$ of $\mathrm{CH}_{4}$, after $1,0.5$, and $2 \%$ again, to verify the absence of any decay in activity or ageing effect due to the high temperature of exposure. All tests were repeated at least three times to assure repeatability (average $12 \mathrm{~h}$ of use for each catalyst): the values reported on all graphs represent the average value of the various tests, with the carbon balance close within $\pm 3 \%$ for all measurements. The light-off temperature $\left(T_{10}\right)$ and the half-conversion temperature $\left(T_{50}\right)$ were regarded as indexes of the catalytic activity of each investigated catalyst.

\section{Results and Discussion}

The XRD patterns of investigated catalysts are shown in Fig. 1. The X-ray diffraction lines characteristic of the cubic cobalt spinel structure were indexed within the $\mathrm{Fd} 3 \mathrm{~m}$ space group (JCPDS card no. 01-080-1533). The diffractograms confirmed the presence of spinel structure in all $\mathrm{Co}_{3} \mathrm{O}_{4}$ samples, no matter with which method it was obtained. Moreover, the spinel structure was preserved after $\mathrm{Pd}$ deposition, with diffractograms revealing no structural changes compared to the pure $\mathrm{Co}_{3} \mathrm{O}_{4}$ carriers, nor diffraction peaks related to $\mathrm{Pd}$ or $\mathrm{PdO}$.

The Raman spectra, registered with an excitation wavelength of $785 \mathrm{~nm}$, confirmed the spinel structure of the cobalt oxide catalysts prepared by both, SCS and precipitation methods (Fig. 2). Five characteristic Raman peaks presented in the Fig. 2 correspond to the $\mathrm{E}_{\mathrm{g}}, 3 \mathrm{~F}_{2 \mathrm{~g}}$ and $\mathrm{A}_{1 \mathrm{~g}}$ vibration modes of the crystalline $\mathrm{Co}_{3} \mathrm{O}_{4}\left(v_{1}=198\right.$ $\left(\mathrm{F}_{2 \mathrm{~g}}\right), v_{2}=486\left(\mathrm{E}_{\mathrm{g}}\right), v_{3}=525\left(\mathrm{~F}_{2 \mathrm{~g}}\right), v_{4}=624\left(\mathrm{~F}_{2 \mathrm{~g}}\right)$, $\left.v_{5}=695 \mathrm{~cm}^{-1}\left(\mathrm{~A}_{1 \mathrm{~g}}\right)\right)$, as discussed in more detail elsewhere [44, 45]. The structural changes of the spinel structure would manifest in an increased asymmetry of the $\mathrm{A}_{1 \mathrm{~g}}$ band as evidenced for $\mathrm{Mg}$ and $\mathrm{Al}$ substituted $\mathrm{Co}_{3} \mathrm{O}_{4}$ [28]. This was not observed, so an excitation wavelength of 
Fig. 1 a XRD patterns of the undoped catalysts obtained by combustion and precipitation synthesis. $\mathbf{b}$ XRD patterns of the 1 wt $\%$ Pd-doped $\mathrm{Co}_{3} \mathrm{O}_{4}$ catalysts obtained by combustion and precipitation synthesis. $1 \% \mathrm{Pd} / \mathrm{Co}_{3} \mathrm{O}_{4}$ catalysts labelled as -OS are prepared by one-shot SCS
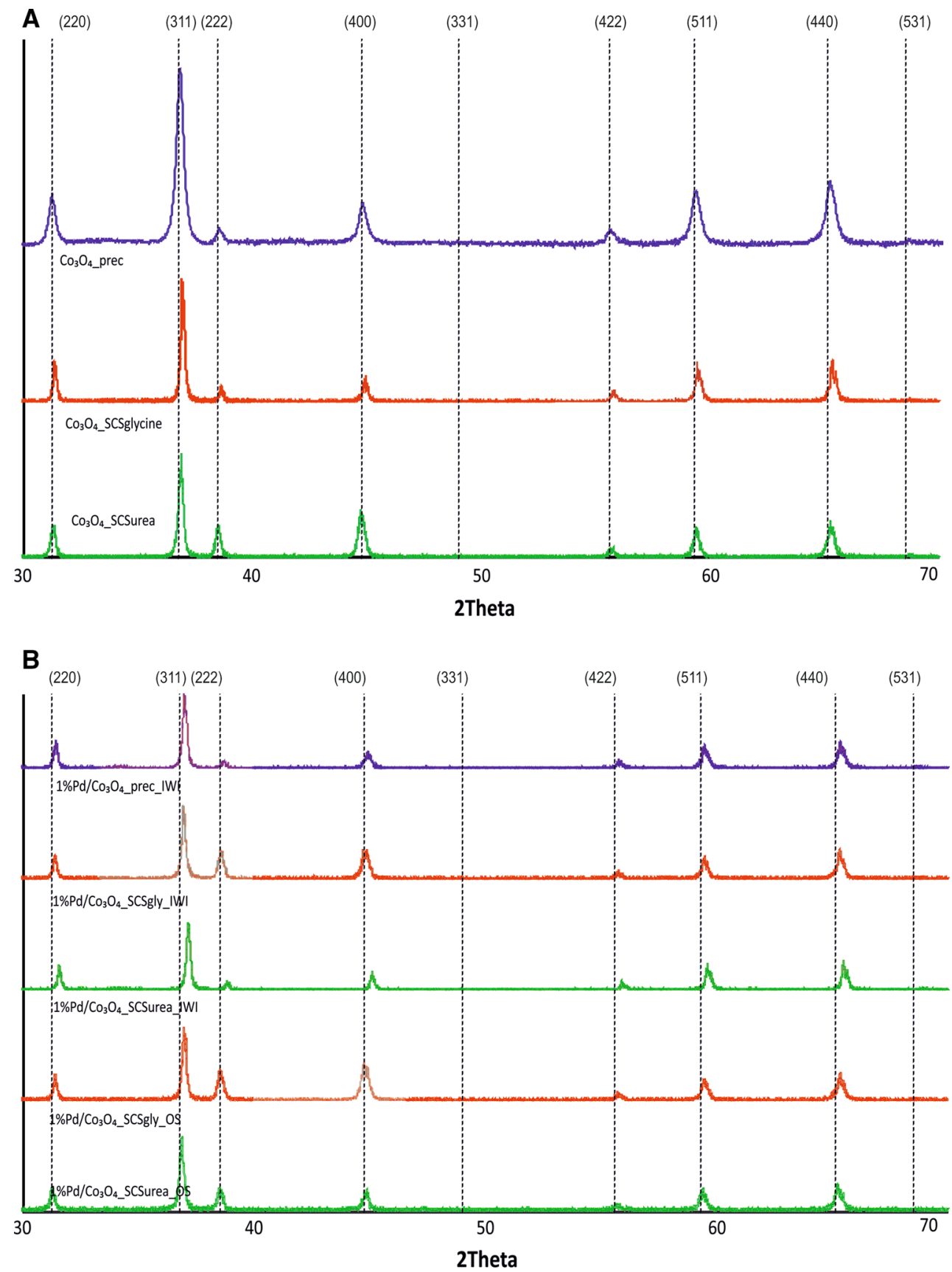

$514 \mathrm{~nm}$ was also used. With this excitation wavelength, the $\mathrm{A}_{1 \mathrm{~g}}$ band of the $\mathrm{Pd}$-doped $\mathrm{Co}_{3} \mathrm{O}_{4}$ can become asymmetrical or even evidently consisting of more than two overlapping peaks. This effect is probably related to the change of cobalt oxidation state [35].

Additionally, in Fig. 3, which represents the spectra of the $\mathrm{Co}_{3} \mathrm{O}_{4}$ samples registered with an excitation wavelength of $514 \mathrm{~nm}$, the asymmetry of the peaks, especially $A_{1 g}$, is observed for SCS prepared samples. It can be attributed to the presence of reduced forms of cobalt oxide $\mathrm{CoO}_{\mathrm{x}}[33,46]$. This phenomenon is not visible for the samples obtained via precipitation method, showing the influence of transient conditions of the synthesis during combustion on the oxidation state of cobalt.

For the samples doped with palladium, a strong asymmetry of the peak $\mathrm{A}_{1 \mathrm{~g}}$ is present for all $\mathrm{Pd} / \mathrm{Co}_{3} \mathrm{O}_{4}$ samples (Fig. 3). The asymmetry can be presented as a ratio of the areas of the low and high wavelength parts of the $\mathrm{A}_{1 \mathrm{~g}}$ band, $n$ (Table 1). The increase in the low wavelength part of the peak upon palladium doping leads to the visible split of this band, also in the case of $1 \% \mathrm{Pd} / \mathrm{Co}_{3} \mathrm{O}_{4}$ precipitation sample. Since the observed rise of the $n$ is related to the 


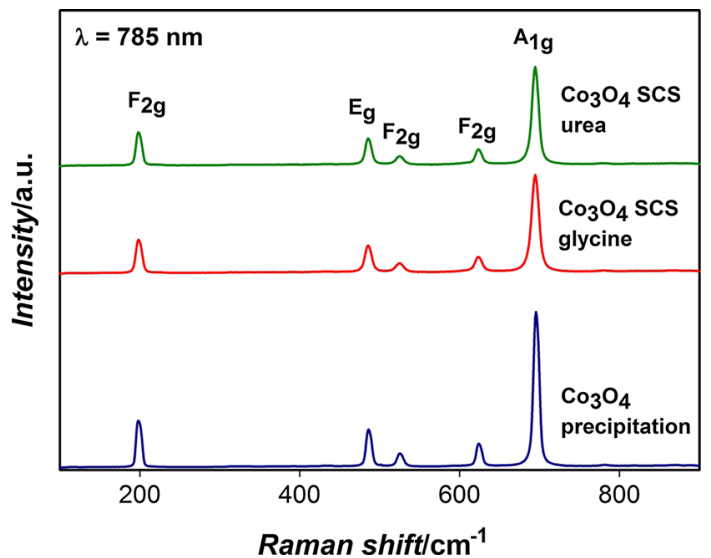

Fig. 2 Raman spectra of $\mathrm{Co}_{3} \mathrm{O}_{4}$ samples obtained with precipitation method and combustion method (with glycine and urea as a fuel) $(\lambda=785 \mathrm{~nm})$

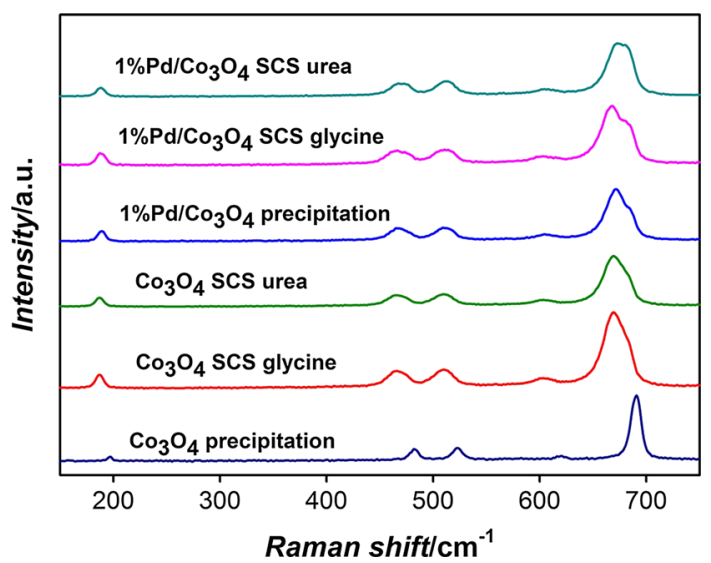

Fig. 3 Raman spectra of $\mathrm{Co}_{3} \mathrm{O}_{4}$ samples obtained with precipitation method and combustion method (with glycine and urea as a fuel) and corresponding samples doped with $1 \mathrm{wt} \%$ of palladium $(\lambda=514 \mathrm{~nm})$

more pronounced presence of $\mathrm{CoO}_{\mathrm{x}}$, the reduction of cobalt oxide caused by $\mathrm{Pd}$ deposition is observed, showing a strong interaction between palladium and cobalt spinel support. The exact values of $n$ appear to be of lesser importance, indicating that more factors influence the catalytic activity. The $\mathrm{A}_{1 \mathrm{~g}}$ band is related to the vibrations of the octahedral units occupied by the $\mathrm{Co}^{3+}$ cations. The splitting is therefore induced by the changes in the local environment of the oxygen ions at the corners of the octahedra. In the simplest model, they can be brought about either by reducing the oxidation state of cobalt to $\mathrm{Co}^{2+}$ or by removal of cobalt and creating a cationic vacancy. In either scenario, the defect concentration increases along with non-stoichiometry of the cobalt spinel.

The results of the elemental composition analysis performed with XRF for the IWI samples $\left(1 \% \mathrm{Pd} / \mathrm{Co}_{3} \mathrm{O}_{4} \mathrm{SCS}\right.$ glycine, $1 \% \mathrm{Pd} / \mathrm{Co}_{3} \mathrm{O}_{4}$ SCS urea, and $1 \% \mathrm{Pd} / \mathrm{Co}_{3} \mathrm{O}_{4}$ precipitation) are summarized in Table 1 . It can be concluded that the obtained loading of palladium was lower that presumed, however, similar for all samples.

The morphology of the undoped and Pd-doped spinels is shown in Figs. 4 and 5. For the undoped spinels, FESEM images point out typical clusters of nanocrystals with the characteristic rhombicuboctahedral shapes, with the prevailing of (100) and (111) planes [47]. Specifically, the spinel prepared by precipitation comprises of the highest amount of the nanocrystals with dimensions below $20-30 \mathrm{~nm}$, which is in agreement with the higher BET specific surface area displayed $\left(31 \mathrm{~m}^{2} \mathrm{~g}^{-1}\right.$, Table 1$)$. In contrast, the two spinel samples prepared by SCS show clusters of bigger dimensions, compatible with lower values of BET specific surface area. Comparing the two spinel samples prepared by SCS, the spinel from glycine appears more sintered, with crystals edges not so clearly defined as for the spinel from urea (Fig. 4). Both samples were prepared with the organic fuel in sub-stoichiometric conditions, with different fuel-to-oxidizer ratio. Depending on the fuel used, in fact, the adiabatic effect can vary, as well as the nature of the combustion-flaming or smoldering (non-flaming) [2]. This could account for the slightly different morphology: on one side, more fuel implied more reducing atmosphere during the SCS synthesis. On the other hand, glycine, a more complex molecule compared to urea, provides more enthalpy per unit of reacting mass [2]. This would imply a higher temperature peak reached
Table 1 Characterization of the prepared catalysts: ratio between Raman peak $\mathrm{A}_{1 \mathrm{~g}}$ components $(n)$ for undoped cobalt spinel and $1 \%$ Pd-doped cobalt spinel catalysts; the bulk (XRF) content of Pd for $1 \%$ Pd-doped catalysts; the BET specific surface area, the BJH adsorption cumulative volume of pores, and the BJH average pore width

\begin{tabular}{llllll}
\hline Sample & $n$ & $\begin{array}{l}\mathrm{Pd} \text { content } \\
{[\%]}\end{array}$ & $\begin{array}{l}\mathrm{S}_{\mathrm{BET}} \\
{\left[\mathrm{m}^{2} \cdot \mathrm{g}^{-1}\right]}\end{array}$ & $\begin{array}{l}\mathrm{V}_{\mathrm{BJH}} \\
{\left[\mathrm{cm}^{3} \cdot \mathrm{g}^{-1}\right]}\end{array}$ & $\begin{array}{l}\mathrm{W}_{\mathrm{BJH}} \\
{[\mathrm{nm}]}\end{array}$ \\
\hline $\mathrm{Co}_{3} \mathrm{O}_{4}$ precipitation & - & - & 31 & n.a. & n.a. \\
$\mathrm{Co}_{3} \mathrm{O}_{4} \mathrm{SCS}$ glycine & 0.024 & - & 4 & 0.0027 & 2 \\
$\mathrm{Co}_{3} \mathrm{O}_{4} \mathrm{SCS}$ urea & 0.024 & - & 14 & 0.0039 & 2 \\
$1 \% \mathrm{Pd} / \mathrm{Co}_{3} \mathrm{O}_{4}$ precipitation & 0.032 & 0.64 & 7 & 0.0005 & 2 \\
$1 \% \mathrm{Pd} / \mathrm{Co}_{3} \mathrm{O}_{4} \mathrm{SCS}$ glycine & 0.052 & 0.63 & 7 & 0.0005 & 2 \\
$1 \% \mathrm{Pd} / \mathrm{Co}_{3} \mathrm{O}_{4} \mathrm{SCS}$ urea & 0.069 & 0.79 & 3 & 0.0008 & 2 \\
$1 \% \mathrm{Pd} / \mathrm{Co}_{3} \mathrm{O}_{4} \mathrm{SCS}$ glycine OS & n.a. & n.a. & 6 & 0.0019 & 2 \\
$1 \% \mathrm{Pd} / \mathrm{Co}_{3} \mathrm{O}_{4} \mathrm{SCS}$ urea OS & n.a. & n.a. & 3 & 0.0008 & 2 \\
\hline
\end{tabular}



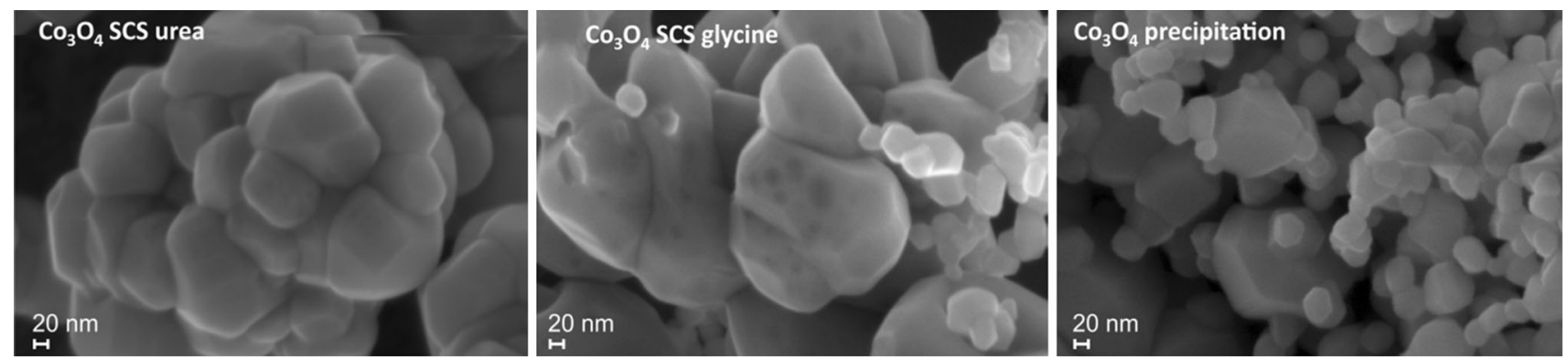

Fig. 4 FESEM images of undoped $\mathrm{Co}_{3} \mathrm{O}_{4}$ samples obtained by different preparation methods
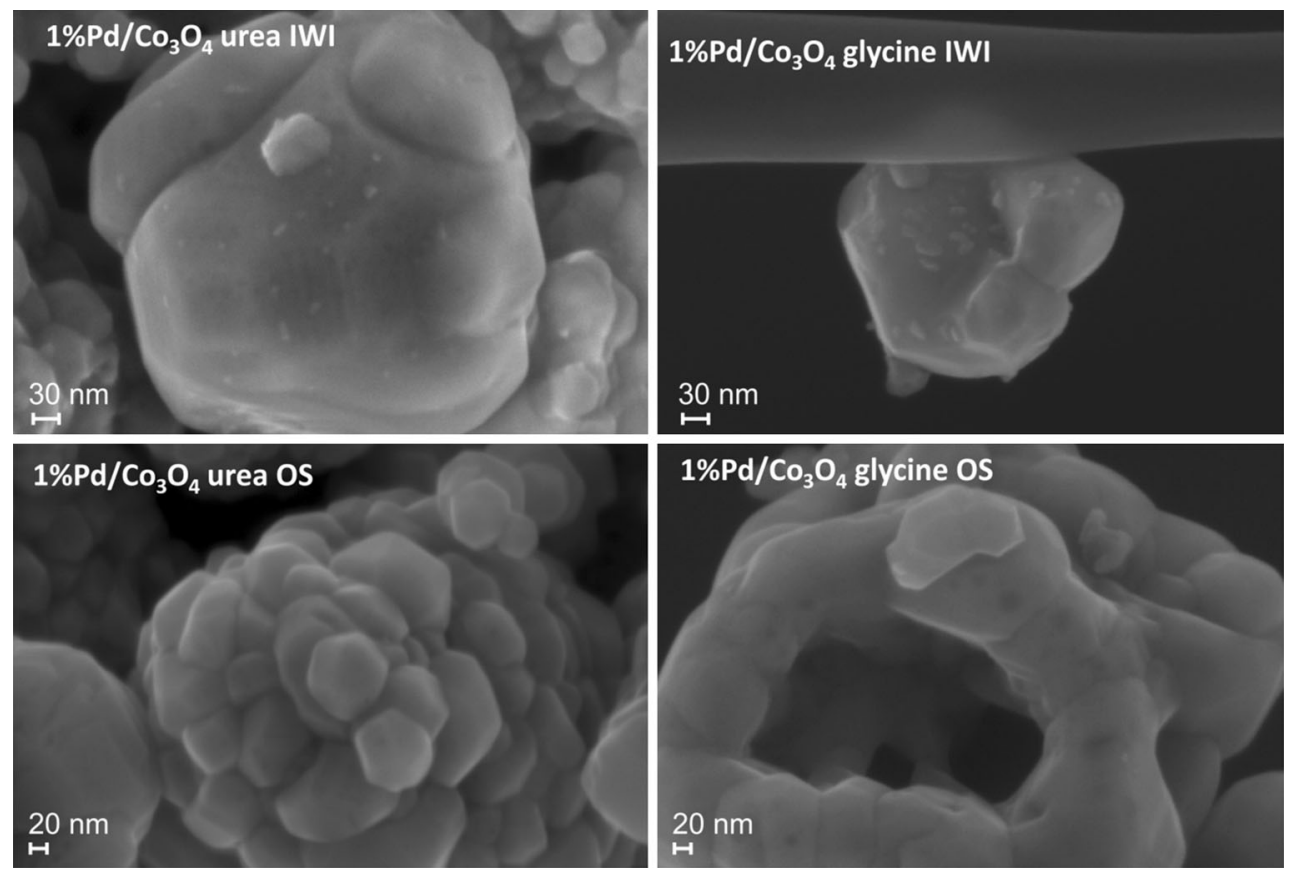

Fig. 5 FESEM images of Pd-doped $\mathrm{CO}_{3} \mathrm{O}_{4}$ samples obtained by different SCS preparation methods

during the combustion synthesis process when glycine is used, explaining why the spinel made from glycine appears more sintered.

For Pd-doped spinel samples (Fig. 5), the basic $\mathrm{Co}_{3} \mathrm{O}_{4}$ nanocrystals with the characteristic rhombicuboctahedral shapes are maintained, independent of the synthesis method (SCS plus IWI or one-shot SCS), and of the organic fuel used. Specifically, for the samples prepared by SCS plus IWI, lighter spots of PdO homogeneously distributed are visible on the surface of the spinel nanocrystal. On the contrary, the one-shot SCS synthesis resulted in palladium oxide incorporated at atomic level into the spinel bulk structure, thus, no PdO spots are visible on the surface [35]. For Pd-doped spinel catalysts, the final BET specific surface area was almost the same for all samples. According to $\mathrm{BJH}$ measurements, all catalysts were roughly non-porous, in agreement with FESEM images.
The comparison of the catalytic activity in methane oxidation reaction (conversion vs. temperature) of the prepared catalysts is shown in Fig. 6 , for different $\mathrm{CH}_{4}$ inlet concentrations: $0.5,1.0$ and $2.0 \mathrm{vol} \%$. The only products formed during the combustion were water (removed prior entering the analyzer in a condenser settled at $3{ }^{\circ} \mathrm{C}$ ), and carbon dioxide. No carbon monoxide was detected in the reactor effluent mixture, in accordance with the high inlet working lambda value. The final combustion tests repeated with $2 \mathrm{vol} \%$ inlet $\mathrm{CH}_{4}$ provided the same results of the first series with $2 \mathrm{vol} \%$, a sign that the behavior of the catalysts was stable for the whole time of testing with different concentrations (approximately $12 \mathrm{~h}$ of time on stream).

From the presented results it can be seen that cobalt oxide prepared via combustion synthesis using urea as a fuel exhibits the highest activity. On the other hand, the 
Fig. 6 Reactivity of the undoped and $1 \mathrm{wt} \%$ Pd-doped $\mathrm{Co}_{3} \mathrm{O}_{4}$ catalysts obtained by combustion and precipitation synthesis in methane oxidation for $2.0 ; 1.0$ and $0.5 \mathrm{vol} \%$ inlet concentration of methane.

$1 \% \mathrm{Pd} / \mathrm{Co}_{3} \mathrm{O}_{4}$ catalysts labelled as -OS are prepared by one-shot SCS
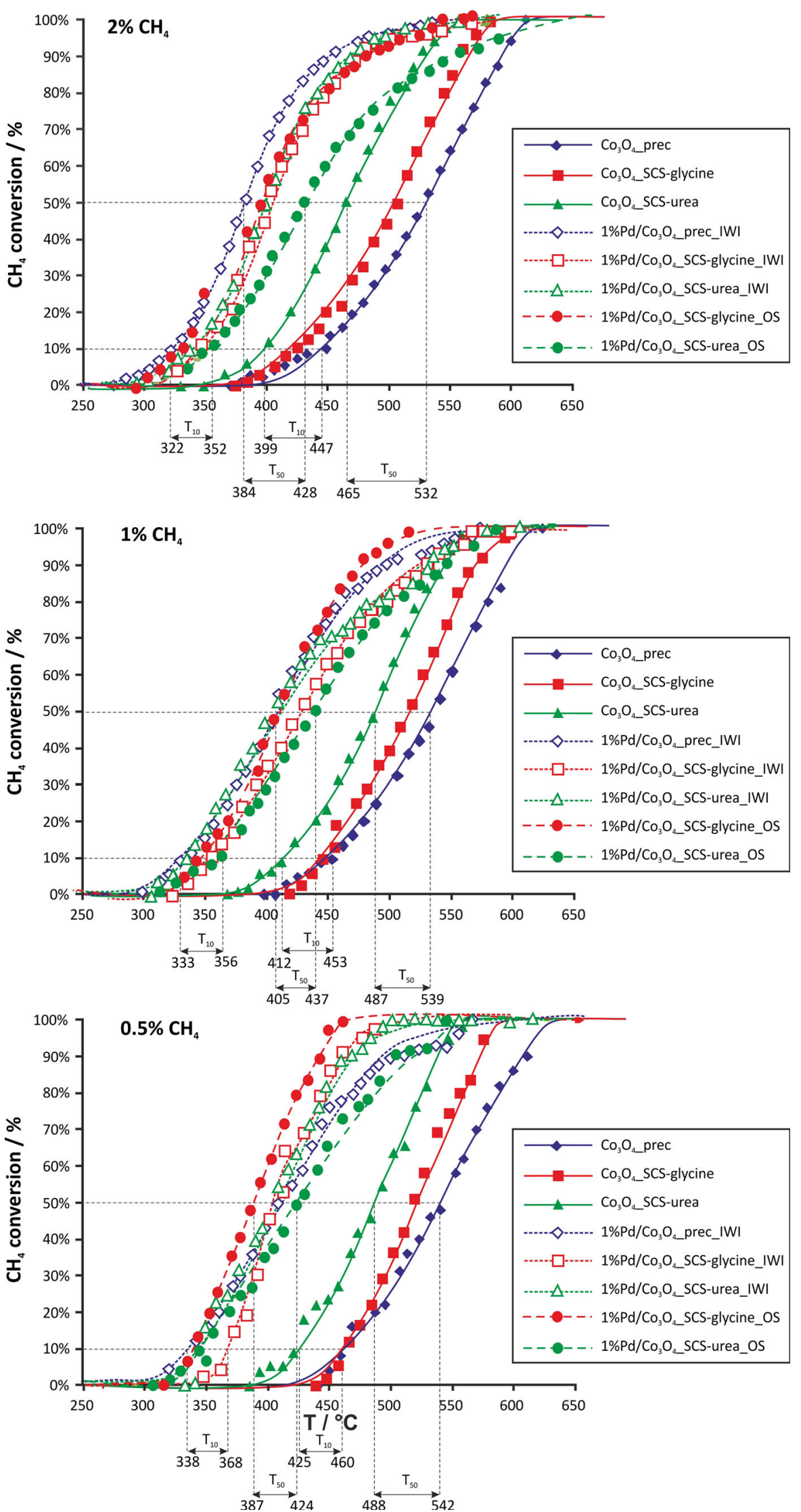
catalyst obtained via precipitation method is the least active one, despite its high SSA. The half conversion temperature for $\mathrm{Co}_{3} \mathrm{O}_{4} \mathrm{SCS}$ urea sample is lower of about $60{ }^{\circ} \mathrm{C}$ in comparison to $\mathrm{Co}_{3} \mathrm{O}_{4}$ precipitation sample. Since the specific surface area for $\mathrm{Co}_{3} \mathrm{O}_{4}$ precipitation (Table 1) is two times higher than for $\mathrm{Co}_{3} \mathrm{O}_{4}$ SCS urea sample the observed difference in catalytic activity cannot be associated with this parameter. Moreover, as shown in Table 1, the $\mathrm{Co}_{3} \mathrm{O}_{4}$ SCS glycine has the lowest specific surface area, while it is also more active than the $\mathrm{Co}_{3} \mathrm{O}_{4}$ precipitation one. Therefore, the observed effect of synthesis method on the catalytic activity of cobalt oxide seems to be related with its redox state, as discussed above.

The promoting effect of $\mathrm{Pd}$-doping on $\mathrm{Co}_{3} \mathrm{O}_{4}$ activity was observed for all the investigated samples, similarly to our previous work [35]. From Fig. 6, it can be noticed that introducing palladium enhances the reactivity of the cobalt catalyst independently on the applied synthesis method, at any $\mathrm{CH}_{4}$ inlet concentration. Moreover, introducing $1 \mathrm{wt} \%$ of $\mathrm{Pd}$ on each investigated $\mathrm{Co}_{3} \mathrm{O}_{4}$ sample leads to almost the same activity. It was shown in Figs. 4 and 5 that the investigated samples present different morphologies. It can be thus concluded that it is rather a chemical modification of $\mathrm{Co}_{3} \mathrm{O}_{4}$ due to palladium doping than the nanostructure which determines its reactivity in methane oxidation. The beneficial effect of palladium deposition on the cobalt oxide can be discussed in terms of cobalt oxide reduction increase revealed by Raman spectroscopy studies.

Considering that methane is a highly stable molecule, it is known that the lower the concentration, the more difficult is its removal from the reactive mixture. This is visible from Fig. 6: by lowering the inlet methane concentrations, $\mathrm{T}_{10}$ and $\mathrm{T}_{50}$ shifted to slightly higher values, for all doped and undoped catalysts. Moreover, careful inspection of Fig. 6 shows that the undoped spinel that performed better (that is, the one produced by SCS with urea, green full curves), gained less as Pd-doped spinel, whereas the better catalytic activities of the Pd-doped spinels (that is, $1 \% \mathrm{Pd} / \mathrm{Co}_{3} \mathrm{O}_{4}$ SCS glycine_OS and $1 \% \mathrm{Pd} / \mathrm{Co}_{3} \mathrm{O}_{4}$ prec IWI) belonged to these catalysts of which the starting undoped spinels performed in a worse way. This means that the promotional effect of $\mathrm{Pd}$ addition is more evident where methane combustion is less effective, that is, for $\mathrm{Co}_{3} \mathrm{O}_{4}$ SCS glycine_OS and $\mathrm{Co}_{3} \mathrm{O}_{4}$ prec IWI catalysts. Furthermore, considering that the most demanding combustion reaction is for the gas mixture containing $0.5 \mathrm{vol} \%$ as methane inlet, we consider the $1 \% \mathrm{Pd} / \mathrm{Co}_{3} \mathrm{O}_{4} \mathrm{SCS}$ glycine_OS catalyst as the most interesting catalyst. Therefore, it can be concluded that one shot synthesis using glycine as a fuel provides the best Pd-doped cobalt oxide catalyst.

\section{Conclusions}

Undoped and $1 \mathrm{wt} \%$ Pd-doped cobalt spinel catalysts were synthesized via precipitation and solution combustion synthesis (SCS) using urea or glycine as precursors, whereas palladium was introduced by incipient wetness impregnation (IWI) or directly during the one-shot synthesis. The catalytic testing toward the lean oxidation of methane, in gas mixtures containing from 0.5 to 2 vol\% of $\mathrm{CH}_{4}$ revealed that the synthesis method influenced the performance, indicating the sample prepared via SCS with urea as the most active one. The addition of Pd improved the catalytic performance of all catalysts independently on the applied synthesis method, at any $\mathrm{CH}_{4}$ inlet concentration, leading to almost the same catalytic activity level. Physical characterization of the catalysts revealed that the beneficial effect of palladium deposition on the cobalt oxide can be linked to a more reduced state of the cobalt oxide. It can be also concluded that the presence of welldefined facets of $\mathrm{Co}_{3} \mathrm{O}_{4}$ nanocrystals is also beneficial for its catalytic activity.

Acknowledgments The authors gratefully acknowledge the Italian project PRIN IFOAMS ("Intensification of catalytic processes for clean energy, low-emission transport and sustainable chemistry using open-cell FOAMS as novel advanced structured materials", protocol n. PRIN-2010XFT2BB) funded by the Italian Ministry of Education, University and Research, and the Executive Programme for Scientific and Technological Cooperation CANALETTO (protocol n. M00478) between the Italian Republic (Ministry of Foreign Affairs) and the Republic of Poland (Ministry of Science and Higher Education). Mr. Mauro Raimondo is gratefully acknowledged for FESEM analyses. Paweł Stelmachowski gratefully acknowledges the financial support from the Polish National Science Center awarded by decision number DEC-2012/05/D/ST5/00210.

Open Access This article is distributed under the terms of the Creative Commons Attribution 4.0 International License (http://crea tivecommons.org/licenses/by/4.0/), which permits unrestricted use, distribution, and reproduction in any medium, provided you give appropriate credit to the original author(s) and the source, provide a link to the Creative Commons license, and indicate if changes were made.

\section{References}

1. Forzatti P, Groppi G (1999) Catal Today 54:165

2. Specchia S, Finocchio E, Busca G, Specchia V (2010) Combustion synthesis. In: Lackner M, Winter F, Agarwal AK (eds) Handbook of combustion. Wiley-VCH Verlag GmbH \& Co. KGaA, Weinheim, pp 439-472

3. Curran SJ, Wagner RM, Graves RL, Keller M, Green JB Jr (2014) Energy 75:194

4. Bielaczyc P, Woodburn J, Szczotka A (2014) Appl Energy 117:134

5. Özgen Karacan C, Ruiz FA, Cotè M, Phipps S (2011) Int J Coal Geol 86:121

6. Su S, Agnew J (2006) Fuel 85:1201 
7. Anifowose B, Odubela M (2015) J Clean Prod 92:121

8. Ríos-Mercado RZ, Borraz-Sánchez C (2015) Appl Energy 147:536

9. Al-Sobhi SA, Elkamel A (2015) J Nat Gas Sci Eng 23:500

10. Stolaroff JK, Bhattacharyya S, Smith CA, Bourcier WL, Cameron-Smith PJ, Aines RD (2012) Environ Sci Technol 46:6455

11. Möllersten K, Grönkvist S (2007) Energy Policy 35:3675

12. de la Peña O'Shea VA, Alvarez-Galvan MC, Requies J, Barrio VL, Arias PL, Cambra JF, Güemez MB, Fierro JLG (2015) Appl Catal B Environ 179:313

13. Kinnunen NM, Hirvi JT, Suvanto M, Pakkanen TA, Molec J (2012) Catal A Chem 356:20

14. Amin A, Abedi A, Hayes R, Votsmeier M, Epling W (2014) Appl Catal A Gen 478:91

15. Bassil J, AlBarazi A, Da Costa P, Boutros M (2011) Catal Today 176:36

16. Miniajluk N, Trawczyński J, Zawadzki M, Tomaszewski PE, Miśta W (2015) Catal Today 257:26

17. Li C, Wang W, Zhao N, Liu Y, He B, Hu F, Chen C (2011) Appl Catal B Environ 102:78

18. Specchia S, Palmisano P, Finocchio E, Larrubia Vargas MA, Busca G (2009) Appl Catal B Environ 92:285

19. Zhang Y, Qin Z, Wang G, Zhu H, Dong M, Li S, Wu Z, Li Z, Wu Z, Zhang J, Hu T, Fan W, Wang J (2013) Appl Catal B Environ 129:172

20. Castaño MH, Molina R, Moreno S, Molec J (2015) Catal A Chem 398:358

21. Wu H, Wu Q, Wang L (2015) Mater Charact 103:1

22. Farhadi S, Pourzare K, Bazgir S (2014) J Alloy Compd 587:632

23. Sun H, Liu Y, Yu Y, Ahmad M, Nan D, Zhu J (2014) Electrochim Acta 118:1

24. Menezes PW, Indra A, Sahraie NR, Bergmann A, Strasser P, Driess M (2015) Chem Sus Chem 8:164

25. Zhang DE, Li F, Chen AM, Xie Q, Wang MY, Zhang XB, Li SZ, Gong JY, Han GQ, Ying AL, Tong ZW (2011) Solid State Sci 13:1221

26. Feng Y, Zheng X (2012) Chem Cat Chem 4:1551-1554

27. Bai B, Arandiyan H, Li J (2013) Appl Catal B Environ 142-143:677
28. Stelmachowski P, Maniak G, Kaczmarczyk J, Zasada F, Piskorz W, Kotarba A, Sojka Z (2014) Appl Catal B 146:105

29. Inger M, Kowalik P, Saramok M, Wilk M, Stelmachowski P, Maniak G, Granger P, Kotarba A, Sojka Z (2011) Catal Today 176:365

30. Chmielarz L, Jabłońska M (2015) RSC Adv 5:43408

31. Zwinkels MFM, Jaras SG, Menon PG, Griffin TA (1993) Catal Rev 35:319

32. Ren Z, Botu V, Wang S, Meng Y, Song W, Guo Y, Ramprasad R, Suib SL, Gao P-X (2014) Angew Chem Int Edit 126:7351

33. Jodłowski PJ, Jędrzejczyk RJ, Rogulska A, Wach A, Kuśtrowski P, Sitarz M, Łojewski T, Kołodziej A, Łojewska J (2014) Spectrochim Acta A 131:696

34. Wang Q, Peng Y, Fu J, Kyzas GZ, Reduwan Billah SM, An S (2015) Appl Catal B Environ 168-169:42

35. Ercolino G, Grzybek G, Stelmachowski P, Specchia S, Kotarba A, Specchia V (2015) Catal Today 257:66

36. Liotta LF, Di Carlo G, Pantaleo G, Deganello G (2007) Appl Catal B Environ 70:314

37. Zavyalova U, Scholz P, Ondruschka B (2007) Appl Catal A Gen 323:226

38. Bahlawane N (2006) Appl Catal B Environ 67:168

39. Wang Y, Zhong Z, Chen Y, Ng CT, Lin J (2011) Nano Res 4:695

40. Hu L, Peng Q, Li Y (2008) J Am Chem Soc 130:16136

41. Inger M, Wilk M, Saramok M, Grzybek G, Grodzka A, Stelmachowski P, Makowski W, Kotarba A, Sojka Z (2014) Ind Eng Chem Res 53:10335

42. Piskorz W, Zasada F, Stelmachowski P, Kotarba A, Sojka Z (2008) Catal Today 137:418

43. Toniolo JC, Takimi AS, Bergmann CP (2010) Mater Res Bull 45:672

44. Wei Y, Nam KW, Kim KB, Chen G (2006) Solid State Ionics 177:29

45. Gasparov LV, Tanner DB, Romero DB, Berger H, Margaritondo G, Forro L (2000) Phys Rev B 62:7939

46. Łojewska J, Knapik A, Jodłowski P, Łojewski T, Kołodziej A (2013) Catal Today 216:11

47. Zasada F, Piskorz W, Stelmachowski P, Kotarba A, Paul J-F, Płociński T, Kurzydzowski KJ, Sojka Z (2011) J Phys Chem C 115:6423 